\title{
Brief Social Defeat Stress: Long Lasting Effects on Cocaine Taking During a Binge and Zif268 mRNA Expression in the Amygdala and Prefrontal Cortex
}

\author{
Herbert E Covington III', Takefumi Kikusui ${ }^{1,5}$, Justin Goodhue', Ella M Nikulina ${ }^{2}$, Ronald P Hammer Jr ${ }^{2,3,4}$ \\ and Klaus A Miczek*, ${ }^{*}, 2,3,4$ \\ 'Department of Psychology, Tufts University, Medford and Boston, MA, USA; ${ }^{2}$ Department of Psychiatry, Tufts University, Medford and Boston, \\ MA, USA; ${ }^{3}$ Department of Pharmacology, Tufts University, Medford and Boston, MA, USA; ${ }^{4}$ Department of Neuroscience, Tufts University, \\ Medford and Boston, MA, USA
}

\begin{abstract}
Social stress can engender behavioral and neural sensitization and this process appears to enhance the transition to compulsive drug abuse. Exposures to brief social defeat stress in rats have significant consequences on cocaine-reinforced behavior and on the level of functional activation within regions of the mesocorticolimbic dopamine system. The objectives of the current study were to examine the enduring consequences of brief episodes of social defeat stress on cocaine bingeing (during $24 \mathrm{~h}$ of continuous access) and on the emergence of neural adaptations as revealed by zif268 immediate early gene expression. Adult, male Long-Evans rats were subjected to four 25 min episodes of social defeat (once every $72 \mathrm{~h}$ ). After 2 months, cocaine binges or zif268 mRNA gene expression were studied after confirming behavioral cross-sensitization to stimulant challenge. Sensitization to social defeat increased cocaine intake during a $24 \mathrm{~h}$ binge, effectively abolishing the typical circadian pattern of intake. Furthermore, 60 days after exposure to the sensitizing regimen of social defeat, levels of functional activation, measured by zif268 mRNA expression, in the central and medial amygdala were increased, while levels of activation in the medial prefrontal cortex were decreased. Persistent stress-induced levels of zif268 in the central and medial amygdala were attenuated by an injection of amphetamine $(1.0 \mathrm{mg} / \mathrm{kg})$. Divergent changes in zif 268 within the amygdala and cortex 2 months after social defeat stress indicate the vulnerability of distinct cellular populations in networks that modulate the behavioral actions of psychomotor stimulants.

Neuropsychopharmacology (2005) 30, 310-321, advance online publication, 20 October 2004; doi:I0.1038/sj.npp. I 300587
\end{abstract}

Keywords: amphetamine; self-administration; immediate early gene; functional activation; rat; drug abuse

\section{INTRODUCTION}

Intermittent exposures to environmental stress can amplify many physiological and behavioral responses to psychomotor stimulants and can accelerate the initiation and maintenance of cocaine use (Miczek and Mutschler, 1996; Goeders, 2002; Sinha, 2001). In particular, brief exposure to social stress increases the rate of acquiring cocaine selfadministration (Haney et al, 1995; Tidey and Miczek, 1997; Kabbaj et al, 2001). Social stress when experienced in an episodic manner can significantly enhance the rate and

\footnotetext{
*Correspondence: Dr KA Miczek, Tufts University, 530 Boston Ave. (Bacon Hall), Medford, MA 02155, USA, Tel: 617627 2453, Fax: 617 627 3939, E-mail: klaus.miczek@tufts.edu, http://www.neurosci.tufts.edu/Miczek/

${ }^{5}$ Current address: Department of Veterinary Medicine, The University of Tokyo, Tokyo, Japan.

Received I4 July 2004; revised 9 September 2004; accepted 10 September 2004

Online publication: 13 September 2004 at http://wnw.acnp.org/citations/ Npp09| 30404323/default.pdf
}

duration of intravenous (i.v.) cocaine taking during $24 \mathrm{~h}$ of continuous access, especially in the latter phase of a binge when cocaine taking becomes dysregulated (Tornatzky and Miczek, 2000). Increased cocaine taking during $24 \mathrm{~h}$ binges persists for at least 2 months after social stress in rats (Covington and Miczek, 2001). Clinically, cocaine bingeing approximates the most serious form of abuse, which is characterized by intense and uncontrollable drug taking that continues for days or until the drug supply is exhausted (Gawin, 1991).

Social defeat is a salient stressor characterized by a distinctive physiological profile and cellular activation of mesocorticolimbic pathways (Miczek et al, 1982; Tidey and Miczek, 1996; Kollack-Walker et al, 1997; Martinez et al, 2002; Miczek et al, 2004). The amygdala and medial prefrontal cortex (mPFC) are essential for initiating appropriate behavioral and physiological responses to stressful challenges, and one of their functions is to maintain control over conditioned reinforced behavior (Doherty and Gratton, 1996; Jentsch and Taylor, 1999; Parkinson et al, 2000; Stevenson and Gratton, 2003). 
Cellular activity in amygdaloid and prefrontal cortical nuclei can be studied by immediate early gene (IEG) expression (Herdegen and Leah, 1998). Zif268, an IEG in the krox family, is constitutively expressed within cells and the amount of its expression correlates with the level of functional activation in neuronal tissue (Worley et al, 1991). Zif268 mRNA expression is rapidly altered by changes in membrane potentials, particularly after drug and stress experiences, indicating adaptive responses in the form of synaptic plasticity (Worley et al, 1991; Honkaniemi et al, 2000; Mutschler et al, 2000).

In a preliminary experiment, we explored the long-term behavioral and neural consequences of four brief episodes of social defeat stress in rats. Upon challenge with a low dose of amphetamine $(1 \mathrm{mg} / \mathrm{kg})$, defeated rats displayed behavioral sensitization 20,40, and 60 days after their last defeat. Using quantitative in situ hybridization, zif 268 mRNA expression was quantified 60 days after the last stress episode and $60 \mathrm{~min}$ after the final amphetamine injection. The basal level of zif268 60 days after stress was assessed in separate groups of rats that were not administered amphetamine. Social defeat-stressed rats, relative to unstressed rats, had significantly greater basal levels of zif268 mRNA expression in the amygdala, and significantly less zif268 expression in the prefrontal cortex. Stress-augmented levels of zif268 expression were attenuated by amphetamine in cortical and amygdaloid nuclei. In contrast, amphetamine significantly potentiates the expression of the transcription factor Fos in the VTA and amygdala 2 months after brief exposure to social defeat stress, indicating divergent neural adaptations as a result of social stress (Nikulina et al, 2004).

The present study investigated, in parallel, both cocaine bingeing and zif268 mRNA expression 2 months after the last of four brief stress episodes, without any intervening challenges. Experiment one examined the effects of social defeat on cocaine self-administration behavior during $24 \mathrm{~h}$ of continuous access to a low unit dose of intravenous cocaine $(0.3 \mathrm{mg} / \mathrm{kg} / \mathrm{infusion})$. Experiment two was designed to corroborate preliminary findings using zif268. Zif268 mRNA expression was quantified 60 days after the last defeat in the nucleus accumbens (NAc) core and shell, dorsal striatum (caudatoputamen), infralimbic and prelimbic cortex, and the central (CeA), medial (MeA), and basolateral (BLA) amygdala of rats that were administered saline or amphetamine $(1.0 \mathrm{mg} / \mathrm{kg}) 60 \mathrm{~min}$ prior to tissue collection. We hypothesized that brief intermittent episodes of social stress increase cocaine self-administration during a $24 \mathrm{~h}$ binge 2 months later. In addition, we postulated that altered zif268 expression within cortical and subcortical brain regions that control behavioral responses to psychomotor stimulants occurs concurrent with the manifestation of compulsive cocaine self-administration behavior.

\section{MATERIALS AND METHODS}

\section{Subjects}

Male Long-Evans rats (Charles River Laboratories, Wilmington, MA) (225-250 g) were individually housed in custom-built clear acrylic chambers $(30 \times 30.5 \times 24.5 \mathrm{~cm})$. Each rat was housed on cellulose $\left(\mathrm{CelluDri}^{\mathrm{TM}}\right)$ pellet bedding (Shepherd Specialty Papers, Kalamazoo, MI) where they had free access to food (Purina Laboratory Chow) and water throughout all phases of each experiment. Rats were continuously maintained on a reversed light cycle $(12 \mathrm{~h}: 12 \mathrm{~h}$, light on and off at 08:00) with controlled temperature $\left(21 \pm 1^{\circ} \mathrm{C}\right)$ and humidity $(35-40 \%)$. The chamber walls were fitted with removable stainless wire mesh panels. To maintain the environmental context consistent throughout all phases of each experiment, each chamber served at various phases of the experimental protocol as the home cage, as the protective chamber for the social stress experiments, and as the self-administration chamber for i.v. cocaine self-administration experiments, because sensitized behavioral responses to stimulants are significantly more robust when drug challenges are administered in the same context as the original presentation of the sensitizing agent (Anagnostaras and Robinson, 1996). All rats were habituated to saline injections for 3 days prior to performing any behavioral measurements, or collecting neural tissue. All experimental procedures were approved by the Tufts University Institutional Animal Care and Use Committee, following the Guide for the Care and Use of Laboratory Animals (National Research Council, 1996).

Additional Long-Evans rats $(n=8)$, weighing $500-600 \mathrm{~g}$ (Charles River Laboratories), served as aggressive stimulus rats (residents). Each resident was housed with a female in a large stainless steel cage $(45.7 \times 71.1 \times 45.7 \mathrm{~cm})$. Residents were selected by demonstrating consistent aggressive behavior toward an intruder rat during regularly scheduled confrontations (Miczek, 1979).

\section{Social Stress-Induced Behavioral Cross-Sensitization to Stimulant Challenge}

Induction of behavioral sensitization. A day prior to the first episode of social defeat, all rats were video-recorded in their home cage to establish prestress baseline measurements of motor activity. Specifically, rats were injected with saline and video samples were collected at 5-10 and 25-30 min after injection. Starting the next day, experimental rats were subjected to a social defeat episode in $72 \mathrm{~h}$ intervals (Covington and Miczek, 2001), between 11:00 and 14:00 h, on experimental days $1,4,7$, and 10 . Unstressed control rats were handled in the same fashion as stressed rats, but remained in the vivarium. The social stress episode consisted of three phases (Tornatzky and Miczek, 1993). The experimental rat's home cage was initially placed within an aggressive resident's cage where the intruder was exposed to the resident's species-typical threats for $10 \mathrm{~min}$ through the protective screens of the cage walls. Second, the experimental intruder was removed from their protective home cage, and a confrontation persisted until the attacks by the resident resulted in defeat (ie the display of $4 \mathrm{~s}$ of supine posture by the intruder), or a maximum duration of $5 \mathrm{~min}$. Third, the conditions of the first phase were repeated so that the experimental rat was again exposed for $10 \mathrm{~min}$ to the resident's threats behind the protective screen of its cage. 
Expression of behavioral sensitization. Before cocaine selfadministration, each defeat stressed $(n=9)$ and unstressed $(n=8)$ control rats' locomotor response to a cocaine $(10.0 \mathrm{mg} / \mathrm{kg}$ ) challenge on day 20 (10 days after the last defeat) was observed. Before the assessment of zif268 mRNA in experiment 2 , stressed $(n=8)$ and unstressed control rats $(n=8)$ received an injection of amphetamine $(1.0 \mathrm{mg} / \mathrm{kg}$ ) on experimental day 70 (for experimental outline, see Figure 1).

All behavioral observations were recorded in the experimental rat's home cage as follows: a saline injection was administered $15 \mathrm{~min}$ prior to the stimulant drug challenge in order to determine baseline measurements of locomotor activity. Immediately after the $15 \mathrm{~min}$ baseline, each rat was administered their stimulant challenge. All stimulant challenges were administered between 11:00 and 14:00. Five min video samples were collected 5-10 min after saline injection, and 5-10 and 25-30 min after stimulant challenges.

An observer using a custom keyboard and commercial software (The Observer Video-Pro ${ }^{\circ}$ v. 4.0, Noldus, Netherlands) analyzed video records after inter- and intraobserver reliability was established. The frequency of walking, rearing, sniffing, grooming, digging, and inactivity were analyzed for each 5 min sample.

\section{Experiment 1: Cocaine Self-Administration}

Experimental procedure and surgery. The day after assessing their locomotor response to a cocaine challenge, both groups of rats were implanted with permanently indwelling catheters (Silastic ${ }^{\circledR}$ silicon tubing, ID $0.63 \mathrm{~mm}$, OD $1.17 \mathrm{~mm}$ ) into the right jugular vein (Remie et al, 1990) under a combination of ketamine $(100 \mathrm{mg} / \mathrm{kg})$ and xylazine $(9 \mathrm{mg} / \mathrm{kg})$ anesthesia. The catheter was passed subcutaneously to the rat's back where it exited through a small incision and was affixed to a plastic pedestal (Plastics One, Roanoke, VA) mounted inside a harness system (Instech

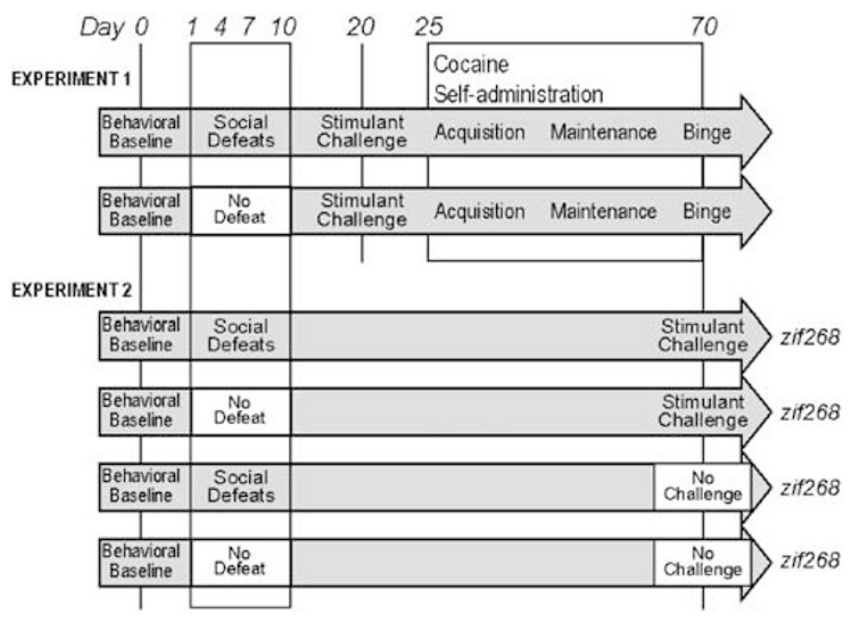

Figure I Separate groups of rats experienced four episodes of social defeat stress over 10 days. After confirming behavioral cross-sensitization to stimulant challenge, defeat-stressed rats and unstressed control rats were examined during a $24 \mathrm{~h}$ cocaine binge (experiment one), or assessed for zif268 mRNA expression (experiment two)
Laboratories Inc., Plymouth Meeting, PA). Rats were allowed to recover from surgery for 5 days.

Self-administration training and maintenance. On the morning after the recovery phase, rats remained in their home cage that was now relocated in a procedure room for i.v. self-administration experiments. The experimental chamber that served as the home cage was placed inside a sound-attenuating outer enclosure. One wall of the experimental chamber was now fitted with a panel containing two retractable levers. Both enclosures had holes in the ceiling to allow a tether (Plastics One) to reach the catheter. The tethered catheter supplied i.v. solutions from a counterbalanced swivel (Instech Laboratories) connected to an infusion pump (Med Associates Inc., St. Albans, VT) (for details, see Miczek and Mutschler, 1996). Catheters were flushed daily with heparinized saline $(20 \mathrm{IU} / \mathrm{ml})$, and during the light phase $0.17 \mathrm{ml}$ pulses of saline were delivered every $30 \mathrm{~min}$. Initially, all rats were allowed to self-administer cocaine $(0.75 \mathrm{mg} / \mathrm{kg} /$ infusion $)$, without a priming infusion, with each lever press being reinforced with an i.v. infusion (ie fixed ratio (FR) 1 schedule of reinforcement) followed by a $30 \mathrm{~s}$ time out. Each daily session was initiated at approximately 10:00 and terminated after 15 infusions or $5 \mathrm{~h}$ of access. The acquisition criterion was defined as 15 infusions within $5 \mathrm{~h}$ over two consecutive days. Behavioral shaping, by applying a small amount of food to the active lever, was initiated to facilitate lever pressing in stressed and unstressed rats that did not meet this criterion within 5 consecutive daily sessions $(25 \mathrm{~h})$. After reliable self-administration behavior was verified (two consecutive days of 15 infusions), the FR schedule was progressively increased to FR 5 (ie every fifth response being reinforced), over the next 5 days. Rats were maintained for at least 10 additional days on an FR 5 schedule of cocaine reinforcement for 15 infusions per day. Finally, rats were allowed continuous access to cocaine during a $24 \mathrm{~h}$ 'binge', with current video recordings of their motor activities. At the completion of the binge, rats were flushed with $0.15 \mathrm{ml}$ of $1 \%$ methohexital sodium to confirm catheter patency. Catheters were considered to be working appropriately if rats showed signs of anesthesia within $2 \mathrm{~s}$ of methohexital delivery.

$24 \mathrm{~h}$ binge protocol. A prolonged access protocol to a lower unit dose of cocaine $(0.3 \mathrm{mg} / \mathrm{kg} /$ infusion $)$ was implemented for a period of $24 \mathrm{~h}$ starting at 19:00, $1 \mathrm{~h}$ before the onset of the light phase. To eliminate external light cues, the houselight remained off and a dim red light was turned on during the entire $24 \mathrm{~h}$ binge. The amount of cocaine administered, number of infusions, interinfusion intervals, and patterns of responding were used as dependent measures. Locomotor activity was monitored continuously starting $1 \mathrm{~h}$ before the binge and ending 1 hour after, by a video-tracking system (Ethovision, Noldus, Netherlands). In addition, 5 min video samples were recorded for each hour of the binge starting $1 \mathrm{~h}$ before, and the last $5 \mathrm{~min}$ sample was collected $1 \mathrm{~h}$ after, the $24 \mathrm{~h}$ binge. Recordings were scored by an observer to identify specific behavioral effects of continuous cocaine intake on walking, rearing, grooming, digging, and focused stereotyped behavior. 
Experiment 2: Zif268 mRNA Expression in the mPFC, NAc, Dorsal Striatum, and Amygdala

Behavioral analysis and experimental procedure. In addition to stressed and unstressed rats that were given a challenge injection of $d$-amphetamine $(1.0 \mathrm{mg} / \mathrm{kg})$ on experimental day 70, separate groups of stressed $(n=8)$ and unstressed control $(n=8)$ rats were administered saline on experimental day 70 one hour before their tissue was collected for zif268 mRNA expression analysis (see Figure 1).

A cohort of socially stressed $(n=5)$ and unstressed control $(n=5)$ rats were included to examine the effects of the stress-sensitizing protocol on zif268 mRNA expression within 7 days of stress exposure. These rats were included for the purpose of capturing constitutive zif268 mRNA expression on experimental day 17. Rats were given an injection of saline $1 \mathrm{~h}$ before tissue collection to remain consistent with day 70 zif $268 \mathrm{mRNA}$ analyses.

Tissue preparation. At $1 \mathrm{~h}$ after saline or amphetamine injection, the animals were anesthetized with sodium pentobarbital and perfused transcardially with cold $0.9 \%$ $\mathrm{NaCl}$, followed by $4 \%$ paraformaldehyde in $0.1 \mathrm{M}$ sodium phosphate buffer ( $\mathrm{pH} 7.4$ ) for $15 \mathrm{~min}$. Brains were removed and transferred to fresh $4 \%$ paraformaldehyde for approximately $12 \mathrm{~h}$. They were cryoprotected with 12.5 and $25 \%$ sucrose, then frozen and stored at $-70^{\circ} \mathrm{C}$. Coronal sections cut at $20 \mu \mathrm{m}$ using a sliding microtome were selected according to Paxinos and Watson (1997) from the frontal cortex (3.0-2.8 from bregma), striatum (1.0-1.2 from bregma), and amygdala ( $-2.3-2.6$ from bregma) and were mounted onto slides, and stored at $-70^{\circ} \mathrm{C}$.

The slides were hydrated in two rinses of buffer solution and acetylated in $0.25 \%$ acetic anhydride in $0.9 \% \mathrm{NaCl} /$ $0.1 \mathrm{M}$ triethanolamine (TEA) for $10 \mathrm{~min}$, then dehydrated for $1 \mathrm{~min}$ in a graded series of ethanol washes as follows: 50, 75 , and $95 \%$ in diethyl pyrocarbonate-treated (DEPC) water and $100 \%$ ethanol. Slides were delipidated in chloroform for $5 \mathrm{~min}$, washed for $1 \mathrm{~min}$ in $100 \%$ ethanol and air-dried for $1 \mathrm{~h}$. All slides were then processed using the same batch of hybridization solution to ensure a homogeneous concentration of probe on all sections.

Probe labeling. Oligodeoxyribonucleotide probe sequence complementary to amino acids $2-16$ of the zif268 protein (5'CCGTTGCTGAGCATCATCTCCTCCAGTTT GGGGTAGT TGTCC $3^{\prime}$ ) was $3^{\prime}$ end labeled with $\left.{ }^{35} \mathrm{~S}\right] \mathrm{dATP}$ (Perkin Elmer Analytical and Life Sciences) utilizing terminal deoxynucleotidyl transferase (Gibco BRL). The procedure for labeling and hybridization of the zif268 oligoprobe has been described previously (Hammer and Cooke, 1996). Briefly, the probe was purified and diluted with hybridization buffer containing $50 \%$ formamide, $500 \mu \mathrm{g} \mathrm{ml}^{-1}$ sheared salmon sperm DNA, $250 \mu \mathrm{g} \mathrm{ml}^{-1}$ yeast tRNA, $4 \times$ salinesodium citrate (SSC), $1 \times$ Denhardt's solution, and $10 \%$ dextran sulfate combined with DTT $(2 \mu \mathrm{l} 5 \mathrm{M}$ DTT/ $100 \mu \mathrm{l}$ solution) in order to yield a $3 \times 10^{7} \mathrm{cpm} / \mathrm{ml}$ hybridization solution. To verify the specificity of the zif268 probe, control slides incorporated hybridization with a sense probe for zif268, and they were included in the current protocol.
In situ hybridization histochemistry. Approximately $100 \mu \mathrm{l}$ of the hybridization solution was added to each slide under sterile coverslips for approximately $16 \mathrm{~h}$ at $37^{\circ} \mathrm{C}$. Coverslips were removed in $1 \times$ SSC and slides were rinsed in $1 \times$ SSC at $23^{\circ} \mathrm{C}$. Slides were then washed four times: $2 \times \mathrm{SSC}$ for $1 \mathrm{~h}$, $1 \times \mathrm{SSC}$ for $1 \mathrm{~h}, 0.5 \times \mathrm{SSC}$ for $30 \mathrm{~min}$, and $0.1 \times \mathrm{SSC}$ at $37^{\circ} \mathrm{C}$ for $30 \mathrm{~min}$ and then rinsed in $0.1 \times \mathrm{SSC}$, washed twice in $1 \times$ SSC for $30 \mathrm{~min}$ and dehydrated again in a series of graded ethanol before being air-dried for $1 \mathrm{~h}$. Dried slides were exposed to Biomax-MR for 4 days and developed with D19 and Rapid Fixer (Kodak).

Image analysis. Regional autoradiographs were assessed in defined brain regions by digitizing them using a CCD camera connected to a Macintosh computer. Neuronal zif268 mRNA expression was measured in prelimbic and infralimbic cortex, NAc core and shell, dorsal striatum, medial, central, and basolateral amygdaloid nuclei. To accomplish accurate and reliable bordering of amygdala nuclei, the NIH-Image method of alignment (version 1.61, $\mathrm{NIH}$ ) for each section of tissue was utilized. Briefly, borders of amygdaloid nuclei were drawn from Nissl-stained sections and digitally transposed onto film images. Film images were aligned and calibrated optical density was measured. Regions of the NAs (ie shell and core), the prefrontal cortex (ie infralimbic and prelimbic cortex), and the dorsal striatum were assessed using a manual outline of each region. Quantification of optical density in all sections was analyzed with image-analysis software (NIH-IMAGE: created by Wayne Rasband, National Institute of Mental Health, Bethesda, MD, and available on the internet at: http://rsb.info.nih.gov/ij/) using calibrated radiostandards (American Radiolabeled Chemicals) to generate a ${ }^{35} \mathrm{~S}$ calibration curve in cpm/mg. Data from the right and left hemispheres of three adjacent sections were combined to generate a mean value for each selected brain region.

\section{Statistical Analysis}

Behavioral cross-sensitization to stimulant challenge. Initial prestress behavioral assessments of locomotor activity were totaled across $5-10$ and $25-30 \mathrm{~min}$. The frequency of each observed behavior was compared between stressed and unstressed treatment groups using student $t$-tests. For determining behavioral sensitization to cocaine on day 20 (before self-administration experiments) and amphetamine on day 70 (before the assessment of zif268 mRNA expression), the frequency of each observed behavior after an initial saline injection across 5-10 and 25-30 min was compared between the treatment groups (stressed and controls) using Student's $t$-tests. The effects of the subsequent stimulant challenge on the frequency of each behavior was also compared across min 5-10 and 25-30 between treatment groups (stressed and controls) using Student's $t$-tests.

Cocaine self-administration. Rates of acquiring selfadministration behavior were analyzed by comparing the proportion of rats to reach acquisition criteria between groups of stressed and unstressed controls using a KaplanMeier Survival Analysis (Miller, 1981) over the first $25 \mathrm{~h}$. Differences in the total amount of accumulated cocaine 
intake $(\mathrm{mg} / \mathrm{kg})$ between stressed and control rats within the $24 \mathrm{~h}$ binge were compared using Student's $t$-test. The diurnal rhythmicity of cocaine self-administration during the binge was assessed for the two treatment groups using the $\chi^{2}$ periodogram (Sokolove and Bushell, 1978). To assess total intake and motor behavior between the two groups during the different activity phases captured by the $24 \mathrm{~h}$ binge, the total amount of cocaine intake and behavioral durations were calculated for (1) the first hour, (2) the subsequent $12 \mathrm{~h}$, that is, the usual inactive phase, and (3) the last $11 \mathrm{~h}$ beginning with the onset of the dark phase. Student's $t$-tests were used to compare the averaged total amount of cocaine intake and total duration of each behavior scored between groups at each of the three phases of the binge.

Zif268 mRNA expression. A separate two-way ANOVA (stress condition $\times$ challenge injection) was performed within each brain region to determine differences between treatment groups for their amount of zif268 mRNA expression, and a Bonferroni correction was used for post hoc analyses. For all analyses, a level of $p<0.05$ was established as the criterion for significance.

\section{RESULTS}

\section{Experiment 1: Social Stress-Induced Behavioral Cross-Sensitization to Cocaine and Cocaine Bingeing}

Before the first social defeat, no significant behavioral differences were found between groups, as revealed by the frequency of any behaviors occurring in response to a baseline saline injection (Figure 2). During social defeat episodes, intruder rats emitted ultrasounds during all three phases of each defeat. The mean number of attack bites each intruder received was $23.4 \pm 1.33$ across all four defeats. On experimental day 20 (ie 10 days after social defeat stress), no significant differences were found between groups in terms of the frequency of occurrence of any behavior in response to an initial saline challenge. By contrast, walking in response to a cocaine challenge $(10.0 \mathrm{mg} / \mathrm{kg})$ was significantly enhanced in previously stressed rats compared to unstressed controls $\left(t_{15}=4.35, p<0.001\right)$ (Figure 2). No other behaviors quantified were significantly different between stressed and unstressed control rats in response to cocaine challenge.

\section{Assessment of Cocaine Self-Administration after Social Stress}

Acquisition. During the first five sessions, exposure to social defeat stress did not enhance the acquisition of i.v. cocaine self-administration behavior at $0.75 \mathrm{mg} / \mathrm{kg} /$ infusion. Approximately $25 \%$ of stressed and unstressed rats acquired lever-pressing behavior for cocaine deliveries without behavioral shaping. In total, unstressed rats acquired the behavior in $42.5 \pm 10.5 \mathrm{~h}$, while stressed rats acquired selfadministration in $37.9 \pm 12.0 \mathrm{~h}$ (data not shown).

$24 \mathrm{~h}$ binge. The total amount of cocaine intake accumulated during acquisition and the additional weeks of daily limited intake was $160 \pm 11.7$ and $180 \pm 11.0 \mathrm{mg} / \mathrm{kg}$ in

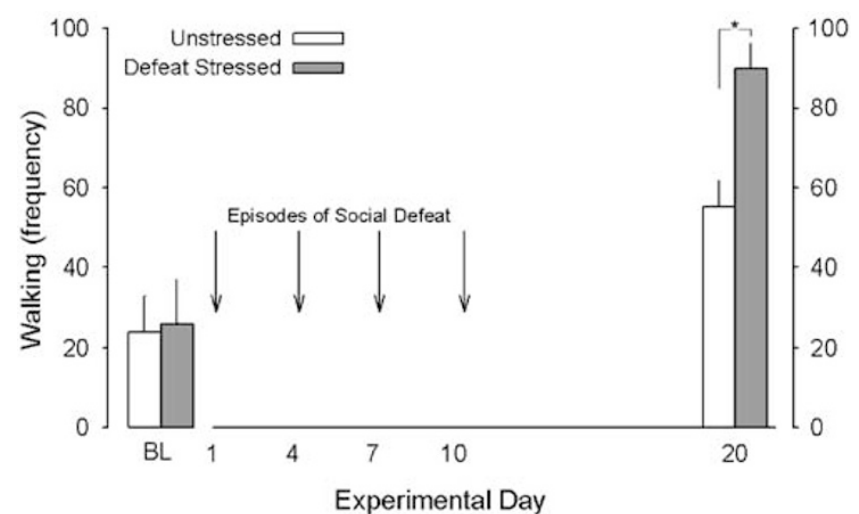

Figure 2 Prior to cocaine self-administration, the effect of a cocaine challenge on the frequency of walking behavior for defeat-stressed rats (gray bars) and unstressed controls (open bars) was examined. Baseline (BL) measurements of walking behavior were obtained after a saline injection before the first stress exposure. Stressed rats received episodes of social defeat on days I, 4, 7, and I0. All rats were challenged with cocaine $(10.0 \mathrm{mg} / \mathrm{kg})$ on day 20 for the expression of sensitization. Bars ( \pm SEM) represent averages for the sum of walking frequency over 5-10 and 25$30 \mathrm{~min}$ postinjection for each group. *Indicate that the means between groups of stressed and corresponding unstressed control rats for that day were significantly different from each other $(p<0.05)$

unstressed and stressed rats, respectively. During the $24 \mathrm{~h}$ binge, stressed rats self-administered significantly more total cocaine than unstressed rats $(108.4 \pm 10.1$ and $67.2 \pm 12.0 \mathrm{mg} / \mathrm{kg}$, respectively) $\left(t_{15}=2.59, p<0.05\right)$. Also, the pattern of hourly cocaine self-administration behavior was significantly different between the two treatment groups. Unstressed rats self-administered cocaine following a diurnal rhythm, indicated by greater intake during the active dark phase and lower intake during the light phase $(\mathrm{Qp}=68.85, p<0.01)$ (Figure 3 top). By contrast, stressed rats self-administered cocaine continuously during the $24 \mathrm{~h}$ binge, indicating an abolished circadian-like pattern of drug taking ( $\mathrm{Qp}=30.35, p>0.05)$ (Figure 3 top). If the binge (with lights off continuously) is divided into previously light and dark phases, stressed rats self-administered significantly more cocaine/h during the first hour $(6.3 \pm 1.1 \mathrm{mg} /$ $\mathrm{kg})$ than unstressed rats $(3.3 \pm 0.6 \mathrm{mg} / \mathrm{kg})\left(t_{15}=2.56\right.$, $p<0.05)$, as well as during the subsequent $12 \mathrm{~h}$ light period $(4.8 \pm 0.5$ ss $1.9 \pm 0.6 \mathrm{mg} / \mathrm{kg} / \mathrm{h})\left(\mathrm{t}_{15}=3.63, p<0.05\right)$. During the final $11 \mathrm{~h}$ of the binge (ie the dark phase), the amount of cocaine intake was similar between stressed $(4.0 \pm 0.5 \mathrm{mg} /$ $\mathrm{kg} / \mathrm{h})$ and unstressed $(3.7 \pm 0.6 \mathrm{mg} / \mathrm{kg} / \mathrm{h})$ rats. Interinfusion intervals were calculated for each animal over the entire binge, and the modal interinfusion interval was $3 \mathrm{~min}$ for stressed rats, and $4 \mathrm{~min}$ for unstressed rats (Figure 4).

Behavioral analysis during the $24 \mathrm{~h}$ binge. Patterns of motor activity expressed during each hour of the binge are indicated by the amount of horizontal locomotor activity $(\mathrm{cm})$ and the duration of stereotyped sniffing (Figure 3 center and bottom). Total horizontal activity and stereotyped sniffing in stressed rats increased promptly upon cocaine availability and decreased as soon as cocaine access was terminated. During the first hour of the binge, stressed rats displayed significantly greater amounts of horizontal activity $\left(t_{15}=2.61, p<0.05\right)$, but not stereotyped behavior 


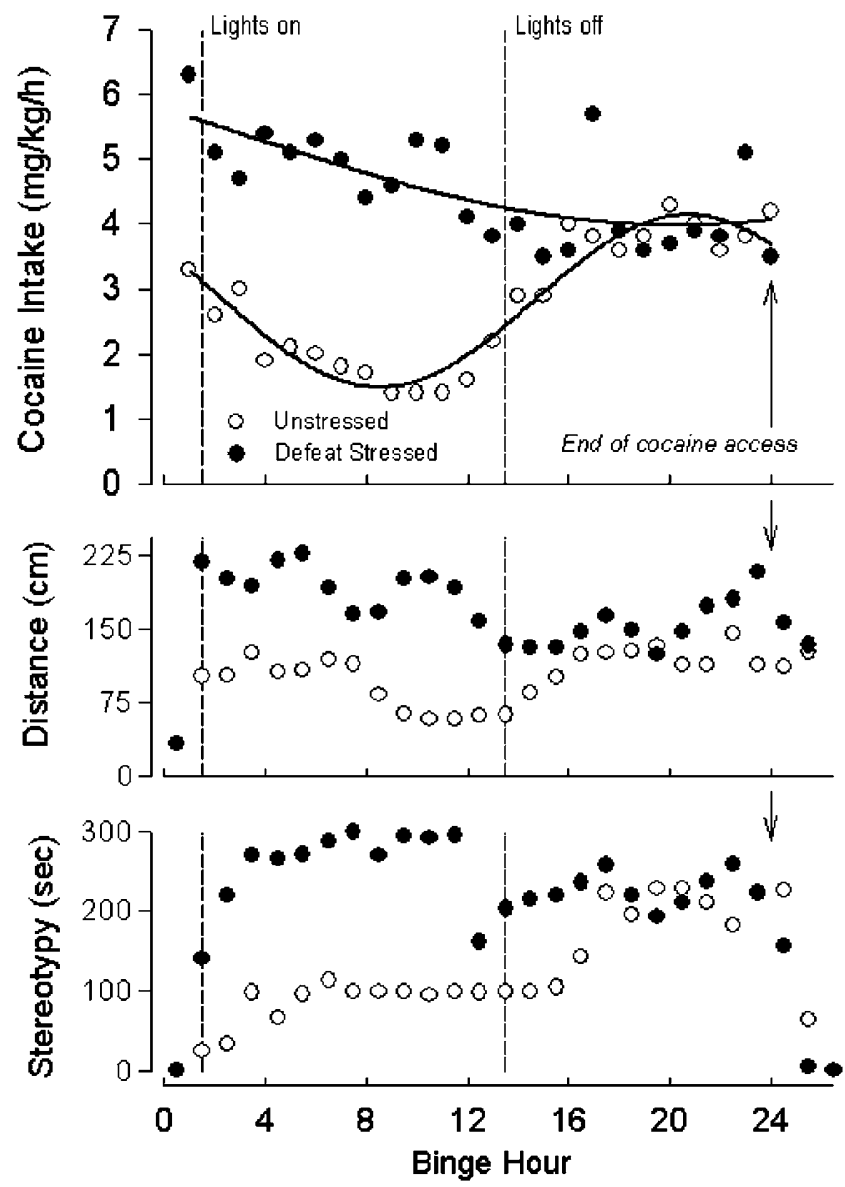

Figure 3 Behavioral assessments during a $24 \mathrm{~h}$ cocaine binge. Upper panel: Hourly cocaine intake is expressed as $\mathrm{mg} / \mathrm{kg} / \mathrm{h}$ for stressed $(n=8)$ and control rats $(n=9)$. Circadian-like cocaine self-administration behavior was maintained in control rats (open circles), whereas stressed rats (filled circles) intensely self-administered cocaine for $24 \mathrm{~h}$ effectively abolishing the circadian pattern of intake $(p<0.0 \mathrm{I})$. Motor activity for each hour of the binge is revealed by the distance $(\mathrm{cm})$ traveled across 5 min bins (center panel), and the duration (s) of focused stereotypies during a 5 min sampling interval (lower panel). Cocaine self-administration curves are fitted with a Weibull equation.

$\left(t_{15}=1.88, p<0.08\right)$. Over the subsequent $12 \mathrm{~h}$ (light phase), stressed rats were again significantly more active as revealed by horizontal activity $\left(t_{15}=2.43, p<0.05\right)$ and stereotyped behavior $\left(t_{15}=4.11, p<0.001\right)$. During the final dark phase (the last $11 \mathrm{~h}$ of the binge), no difference in the amount of horizontal activity, or stereotyped behavior were found between previously stressed and nonstressed rats.

\section{Experiment 2: Social Stress-Induced Behavioral Cross-Sensitization to Amphetamine and Zif268 mRNA Expression}

On experimental day 70 , behavioral analyses revealed that four brief episodes of social defeat stress significantly increased walking behavior after an amphetamine challenge (ie 60 days after the last stress episode), when compared to unstressed rats $\left(t_{14}=3.43, p<0.01\right)$ (Figure 5). Other behaviors observed did not differ significantly between stressed and unstressed control rats in response to

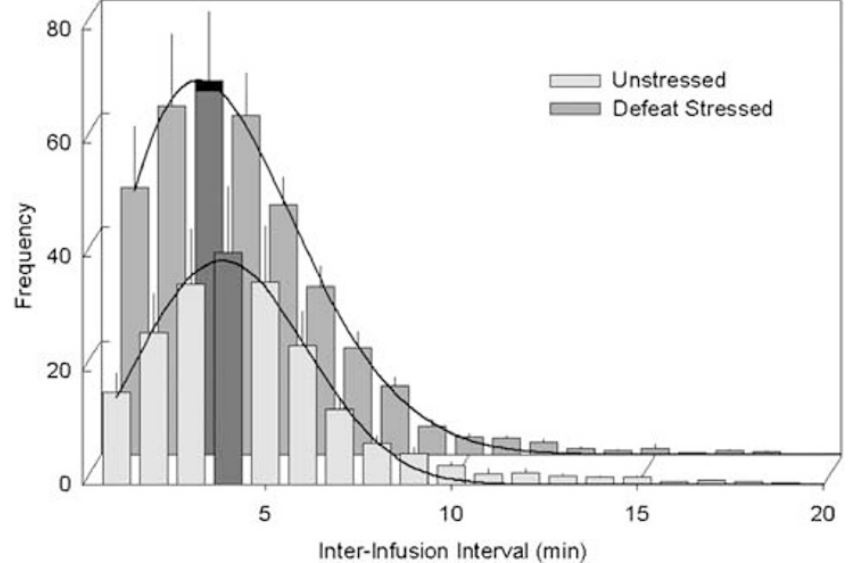

Figure 4 The average number of infusions that occur following particular postinfusion intervals (min). Stress-sensitization (dark gray bars) increased the total frequency of infusions compared to unstressed controls (light gray bars) at each interinfusion interval during the $24 \mathrm{~h}$ binge. In addition, the modal interinfusion interval was decreased in stressed rats by I min (black bars).

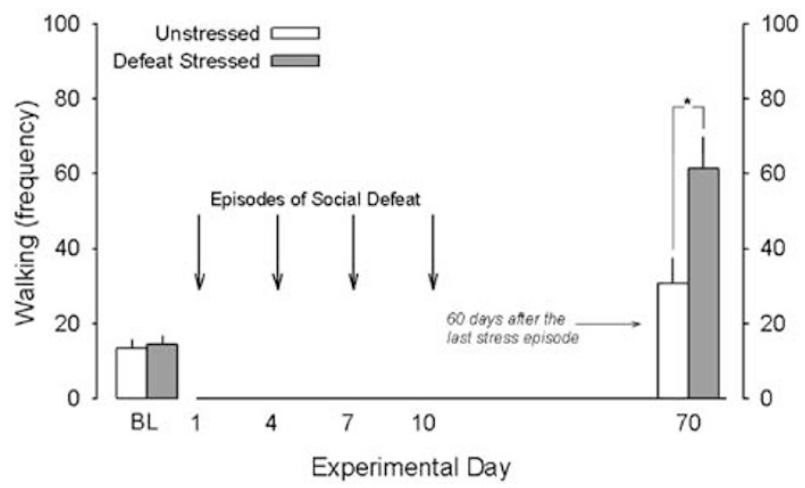

Figure 5 Prior to the analysis of zif268 mRNA expression, the effect of an amphetamine challenge on the frequency of walking behavior for defeatstressed rats (gray bars) and unstressed controls (open bars) was examined. Baseline (BL) measurements of walking behavior were obtained after a saline injection before the first stress exposure. Stressed rats received episodes of social defeat on days I, 4, 7, and 10. All rats were challenged with amphetamine $(1.0 \mathrm{mg} / \mathrm{kg})$ on experimental day 70 for the expression of behavioral sensitization. Bars $( \pm$ SEM) represent averages for the sum of walking frequency over 5-10 and 25-30 min postinjection for each group. *Indicate that the means between groups of stressed and corresponding unstressed control rats for that day were significantly different from each other $(p<0.05)$.

amphetamine. Subsequent to behavioral assessments, these rats were sacrificed and tissue was collected for zif268 mRNA analyses.

Zif268 mRNA expression 60 days after stress. An interaction between stress experience and amphetamine injection was found in zif268 mRNA expression in the CeA on experimental day $70\left(\mathrm{~F}_{1,28}=11.3, p<0.01\right.$; Figure 6$)$. Zif268 mRNA expression in the CeA was greater in stressed rats when compared to unstressed rats $(p<0.05)$. In addition, amphetamine significantly reduced zif268 mRNA expression in the CeA within stressed rats $(p<0.05)$. An interaction between stress experience and amphetamine 

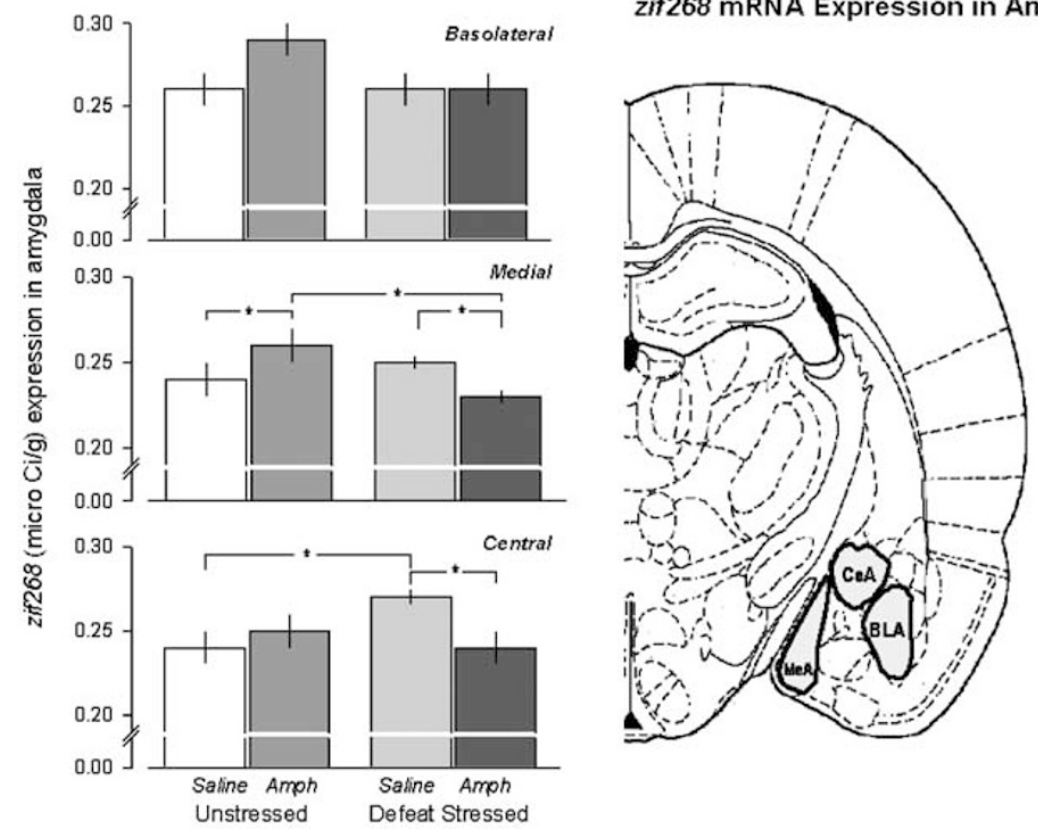

Figure 6 Zif268 mRNA expression in regions of the amygdala, 60 days after four episodes of social defeat stress or after no social defeat. Four cohorts of stressed or unstressed rats received amphetamine ( 1.0$)$ or saline challenges on experimental day 70 ( $n=8$, each). *Indicates that the means between groups are significantly different from each other $(p<0.05)$. Also shown is a coronal illustration of the amygdaloid complex selected for zif268 mRNA analyses.

injection in zif268 mRNA expression was also found in the MeA on experimental day $70\left(\mathrm{~F}_{1,28}=11.4, p<0.01\right.$; Figure 6$)$. Zif268 mRNA expression in the MeA was significantly less in stressed rats when compared to unstressed rats after an amphetamine injection on day $70(p<0.05)$. In addition, amphetamine significantly reduced zif268 mRNA expression in the MeA within stressed rats $(p<0.05)$. Finally, amphetamine significantly increased zif268 mRNA expression in the MeA in unstressed control rats $(p<0.05)$. A main effect of stress experience was found in the infralimbic and prelimbic cortex on day $70\left(\mathrm{~F}_{1,28}=10.2, p<0.01 ; \mathrm{F}_{1,28}=6.4\right.$, $p<0.05$, respectively). In the infralimbic cortex, zif268 mRNA expression in stressed rats was significantly less than unstressed control rats on day $70(p<0.05$; Figure 7$)$. No main, or interaction, effects of stress or amphetamine were found concerning zif268 mRNA expression in the BLA, the shell or core of the NAc, or the dorsal striatum (Table 1).

Zif268 mRNA expression 7 days after stress. No significant difference in the amount of zif268 mRNA expression between stressed and unstressed rats was found in any region of the amygdala, cortex, accumbens, or dorsal striatum 7 days after the last stress episode (Table 2), $1 \mathrm{~h}$ after an injection of saline. It is noteworthy, however, that a reduction of zif $268 \mathrm{mRNA}$ expression in the infralimbic cortex was approaching significance 7 days after social defeat stress $\left(t_{8}=2.15, p=0.06\right)$.

\section{DISCUSSION}

More than 2 months after four brief episodes of social defeat stress, enduring changes in the behavioral response to an amphetamine challenge, cocaine intake during a binge, and cellular activity in the mPFC and amygdala persist. Extending earlier reports (Covington and Miczek, 2001), an episode of social defeat once every $72 \mathrm{~h}$ over 10 days sensitized the motor response to cocaine or amphetamine, for at least 2 months. Stressed rats also self-administered significantly more cocaine during a $24 \mathrm{~h}$ continuous access protocol conducted 2 months after the last defeat. Intensified cocaine bingeing was characterized by an abolishment of the typical circadian pattern of drug taking and shorter interinfusion intervals (Fitch and Roberts, 1993; Tornatzky and Miczek, 2000). Additional evidence shows that persistent cross-sensitization from social defeat stress to amphetamine is associated with distinctive neural adaptations. Using zif $268 \mathrm{mRNA}$ expression as an indicator, long-lasting social stress-induced behavioral sensitization corresponded to an increase in functional activation within discrete nuclei of the amygdala and reduced activation within the mPFC for at least 2 months.

The salience of uncontrollable and unpredictable stressors, such as social defeat, has internal and face validity. Brief episodes of social defeat stress sensitize specific behavioral, physiological, and neural responses to subsequent stressors and stimulant challenges (Nikulina et al, 1998; Miczek et al, 1999b; Nikulina et al, 1999; Covington and Miczek 2001; Nikulina et al, 2004). In the current study, defeat was operationally defined by a prompt display of prolonged submissive-supine postures and the emission of $22 \mathrm{kHz}$ vocalizations (Thomas et al, 1983; van der Poel and Miczek, 1991; Covington and Miczek, 2003). Intruders continue to show robust hyperthermia and tachycardia during subsequent confrontations without signs of habituation (Tornatzky and Miczek, 1994). Social defeat and psychomotor stimulants both increase levels of extracellular dopamine (DA) in the NAc and PFC, and this form of social 


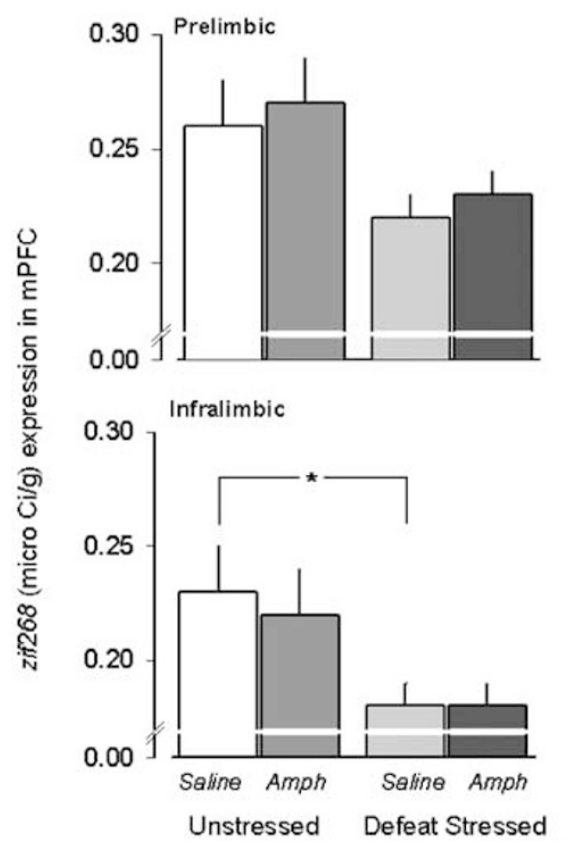

Zif268 mRNA Expression in Cortex

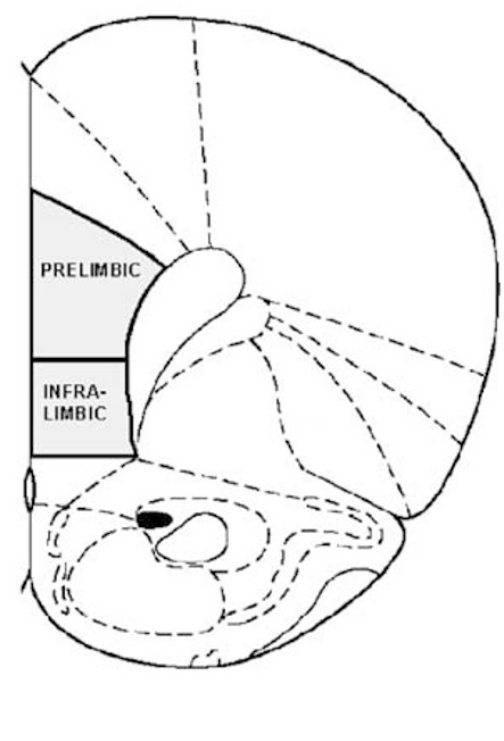

Figure 7 Zif268 mRNA expression in regions of the mPFC, 60 days after four episodes of social defeat stress or no social defeat. Four cohorts of stressed or unstressed rats received amphetamine (I.0) or saline challenges on experimental day 70 ( $n=8$, each). *Indicates that the means between groups are significantly different from each other $(p<0.05)$. Also shown is a coronal illustration of the mPFC areas selected for zif268 mRNA analyses.

Table I Regional zif268 Messenger RNA Expression ( $\mu \mathrm{Ci} / \mathrm{g} \pm \mathrm{SEM}$ ) on Experimental day 70 in Groups of Stressed and Unstressed Control Rats I h after an Initial Saline or Amphetamine $(1.0 \mathrm{mg} / \mathrm{kg})$ Challenge

Unstressed controls

Defeat stressed

\begin{tabular}{|c|c|c|c|c|}
\hline \multirow[b]{2}{*}{ Structure } & & \\
\hline & Saline & Amphetamine & Saline & Amphetamine \\
\hline Prelimbic cortex & $0.263 \pm 0.017$ & $0.273 \pm 0.020$ & $0.224 \pm 0.012$ & $0.230 \pm 0.014$ \\
\hline Infralimbic cortex & $0.228 \pm 0.017^{\mathrm{a}}$ & $0.218 \pm 0.018$ & $0.179 \pm 0.010^{\mathrm{a}}$ & $0.179 \pm 0.007$ \\
\hline NAc shell & $0.219 \pm 0.008$ & $0.224 \pm 0.014$ & $0.235 \pm 0.011$ & $0.224 \pm 0.014$ \\
\hline NAc core & $0.202 \pm 0.009$ & $0.214 \pm 0.011$ & $0.224 \pm 0.011$ & $0.214 \pm 0.017$ \\
\hline Dorsal striatum & $0.282 \pm 0.013$ & $0.320 \pm 0.032$ & $0.316 \pm 0.017$ & $0.331 \pm 0.032$ \\
\hline Basolateral amygdala & $0.259 \pm 0.010$ & $0.289 \pm 0.010$ & $0.260 \pm 0.005$ & $0.258 \pm 0.010$ \\
\hline
\end{tabular}

andicates significant differences between unstressed and stressed rats $(p<0.05)$.

Indicates significant differences between unstressed saline- and unstressed amphetamine-treated rats $(p<0.05)$.

Indicates significant differences between unstressed and defeat-stressed amphetamine-treated rats $(p<0.05)$.

${ }^{d}$ Indicates significant differences between stressed saline- and stressed amphetamine-treated rats $(p<0.05)$.

stress can produce an interoceptive cue that is nondiscriminable from a moderate dose of $d$-amphetamine or cocaine (Tidey and Miczek, 1997; Miczek et al, 1999a). An important feature of the present stress manipulations is their episodic nature, which differs from the life-threatening effects of continuous subordination stress (Blanchard et al, 1985; Miczek et al, 1991; Von Holst, 1998; Lucassen et al, 2001; Carr, 2002).

The results following a $24 \mathrm{~h}$ binge confirm the observation that stress-sensitization increases continuous cocaine self- administration behavior (Covington and Miczek, 2001). Prolonged access to cocaine engenders neural, endocrine, autonomic, and behavioral adaptations not seen after daily limited access (Markou and Koob, 1991; Parsons et al, 1995; Mutschler and Miczek, 1998; Mantsch et al, 2001; Mutschler et al, 2001). Furthermore, access to cocaine exceeding 12$16 \mathrm{~h}$ reveals a transition from regular patterns of responding to behavioral dysregulation (Kreek and Koob, 1998). The loss of regulated drug taking during binges is accompanied by a disruption in physiological and behavioral homeostasis 
Table 2 Regional zif268 Messenger RNA Expression $(\mu \mathrm{Ci} / g \pm \mathrm{SEM})$ in the Cortex, Amygdala, and Striatum 7 Days after Four Episodes of Social Defeat Stress

\begin{tabular}{lll}
\hline Structure & Unstressed & Defeat stressed \\
\hline Prelimbic cortex & $0.190 \pm 0.012$ & $0.190 \pm 0.004$ \\
Infralimbic cortex & $0.186 \pm 0.012$ & $0.158 \pm 0.006$ \\
NAc shell & $0.142 \pm 0.007$ & $0.144 \pm 0.009$ \\
NAc core & $0.138 \pm 0.010$ & $0.136 \pm 0.008$ \\
Dorsal striatum & $0.184 \pm 0.008$ & $0.172 \pm 0.004$ \\
Medial amygdala & $0.124 \pm 0.004$ & $0.128 \pm 0.008$ \\
Central amygdala & $0.138 \pm 0.002$ & $0.140 \pm 0.007$ \\
Basolateral amygdala & $0.142 \pm 0.006$ & $0.148 \pm 0.009$ \\
\hline
\end{tabular}

(Tornatzky and Miczek, 2000). In the present experiments, escalated cocaine intake occurred in stressed rats without a high degree of variation between consecutive interinfusion intervals, even late in the binge. Likewise, intense stereotyped sniffing began within the first hour of the $24 \mathrm{~h}$ cocaine binge in stressed rats. Clearly, cocaine-induced stereotyped motor routines can coexist with an individual's control over self-administering cocaine.

The unit dose is a major variable for quantitatively and qualitatively predicting patterns of continuous cocaine self-administration behavior (Fitch and Roberts, 1993). During extended periods of access, lower doses of cocaine $(<0.5 \mathrm{mg} / \mathrm{kg} /$ infusion) establish patterns of intake that follow a circadian pattern, and intake occurs primarily during the dark phase in the nocturnal rat over consecutive days (Carroll et al, 1989; Fitch and Roberts, 1993). Circadian control is abolished when higher doses of cocaine ( $>0.5 \mathrm{mg} / \mathrm{kg} /$ infusion) are made available. In this case, drug taking overrides endogenous circadian influences and becomes the controlling event. In contrast to our initial report on stress-induced cocaine bingeing (Covington and Miczek, 2001), the present study utilized a lower unit dose of cocaine $(0.3 \mathrm{mg} / \mathrm{kg} /$ infusion $)$, and access was made available $1 \mathrm{~h}$ prior to the onset of the light phase. The amount of cocaine self-administered during the first hour of the binge was significantly different between stressed and nonstressed rats. Unstressed rats self-administered about $3.5 \mathrm{mg} / \mathrm{kg}$ before decreasing intake promptly at the usual onset of inactivity, or the start of the light phase. However, previously defeated rats accumulated almost $6.5 \mathrm{mg} / \mathrm{kg}$ during the first hour and no reduction of intake occurred in these rats during the light phase. Interestingly, the amount of cocaine self-administered does not appear to be a variable that underlies the cessation of cocaine taking during binges, because nonstressed rats will cease cocaine self-administration during the light phase after $10-11 \mathrm{~h}$ of continuous cocaine self-administration (after accumulating approximately $130 \mathrm{mg} / \mathrm{kg}$ Covington and Miczek, 2001). Continuous cocaine bingeing also occurs after pharmacologically induced behavioral sensitization to either stimulants, or opiates (Covington and Miczek, 2001). One possible explanation for the increase in cocaine taking is that sensitization shifts the dose effect curve of self-administered cocaine to the left. However, stress-, cocaine-, and morphine-sensitized rats self-administer a range of doses, including 0.3, 0.75, and $1.5 \mathrm{mg} / \mathrm{kg} /$ infusion, at rates and interinfusion intervals similar to those of nonsensitized rats (Covington and Miczek, 2001).

The induction of stress-sensitization did not augment the rate of acquiring self-administration behavior at this moderately high dose of cocaine $(0.75 \mathrm{mg} / \mathrm{kg} /$ infusion $)$. Lower unit doses might have revealed more subtle differences with respect to acquisition (Carroll et al, 2002). Motor activation in response to novel stressors and experimentally elevated levels of transcription factors in the striatum correlate well with rapid acquisition of 'low dose' cocaine self-administration behavior (Piazza et al, 2000; Mantsch et al, 2001; Colby et al, 2003). Perhaps more pertinent to the acceleration of initial drug taking, even at higher doses, is the immediate activational effect of social stress (Tidey and Miczek 1997; Miczek and Mutschler, 1996).

After episodic sensitizing stress experiences, long-lasting changes in the amount of zif268 mRNA expression within the MPFC and amygdala were observed. Altered constitutive levels of zif268 represent an adaptive cellular response in the form of functional activity. We postulate that elevations in the functional activity of CeA cells are a direct result of the stress-induced deficit in $\mathrm{MPFC}$ activation. Episodic stress-induced increases of DA and glutamate in the mPFC (Perez-Jaranay and Vives, 1991; Tidey and Miczek, 1996) may represent the substrate underlying the observed social stress-induced deficit of mPFC functional activity. The mPFC directly inhibits the activity of amygdala neurons, and cortical inhibition of the $\mathrm{CeA}$ overrides other inputs to the $\mathrm{CeA}$, including that from the BLA (Rosenkranz and Grace, 2001; Quirk et al, 2003). Thus, reduced functional activation of the mPFC after social stress could lead to increased zif268 mRNA expression in the CeA. The hypothesis that adaptations in the amygdala and cortex occur as a direct result of stress-induced DA release is strengthened by our observation that a low-dose of amphetamine $(1.0 \mathrm{mg} /$ $\mathrm{kg}$ ) produced the expression of behavioral sensitization, in addition to attenuating the long-lasting intracellular effects of stress. Specifically, amphetamine weakened the suppressive effect of stress on the functional activity of cells in the $\mathrm{CeA}$ and $\mathrm{MeA}$ (see Figure 6). Interestingly, administration of cocaine in cocaine-dependent individuals reduces the functional activity of amygdaloid neurons, and this inhibition has been suggested to correlate with cocaine craving (Breiter et al, 1997). Electrophysiological studies indicate that infralimbic projection neurons synapse directly onto GABAergic intercalated cells in the CeA (Sesack et al, 1989; Royer et al, 1999; Quirk et al, 2003), which may be the source of amphetamine-induced decreases in functional activation in the $\mathrm{CeA}$ as observed herein.

We observed that amphetamine reduced zif268 mRNA expression in amygdaloid regions, while the same dose of amphetamine increased the number of amygdala neurons expressing Fos, 60 days after social defeat stress (Nikulina et al, 2004). At least two possibilities can account for the difference in amygdaloidal Fos and zif268 expression in 
response to amphetamine after stress exposure. First, discrete populations of neurons may express either elevated Fos or reduced zif268. Neurons exhibiting decreased zif268 mRNA may receive axons from intercalated cells and are profoundly inhibited following amphetamine-induced prefrontal cortex stimulation (Quirk et al, 2003), while CeA cells that express Fos could be activated by intraamygdaloid or thalamic afferents, but may not be targeted by GABAergic inhibition of intercalated neurons (Pare et al, 2003). Second, the functional role of zif268 and Fos may differ within the same cell, as a result of divergent intracellular signaling pathways. For example, the reconsolidation of long-term memory is dependent on zif268, but not other transcription factors (Lee et al, 2004). Likewise, $c$ fos expression is not correlated as tightly as zif268 expression with the synaptic enhancement of hippocampal cells in response to electrical stimulation (Worley et al, 1993). Although environmental stimuli can clearly regulate $c$-fos and zif268 expression, additional experiments are necessary to clarify the divergent functional roles of these IEGs within the same cell groups in response to stressful provocations.

\section{CONCLUSION}

The observed changes in zif268 mRNA expression and cocaine self-administration binges provide further support for the enduring nature of behavioral sensitization to social stress and its postulated link to compulsive drug taking. These data confirm and extend results demonstrating that the $\mathrm{mPFC}, \mathrm{CeA}$, and MeA are persistently altered by stress manipulations, possibly involving morphological changes (Robinson et al, 2001). Our data support the hypothesis that intermittent pulses of stress trigger long-term intracellular effects that may contribute to locomotor sensitization, the facilitation of goal-directed behavioral responses, particularly behavioral responses to stimulant administrations, and intense cocaine self-administration (Sesack and Pickel, 1992; Pierce and Kalivas, 1997).

\section{ACKNOWLEDGEMENTS}

We thank Thomas Sopko for his outstanding contributions to the experiments and the preparation of the manuscript. This research was supported by USPHS research grants DA02632 (KAM) and DA14327 (EMN).

\section{REFERENCES}

Anagnostaras SG, Robinson TE (1996). Sensitization to the psychomotor stimulant effects of amphetamine: modulation by associative learning. Behav Neurosci 110: 1397-1414.

Blanchard RJ, Blanchard DC, Flannelly KJ (1985). Social stress, mortality and aggression in colonies and burrowing habitats. Behav Processes 11: 209-213.

Breiter HC, Gollub RL, Weisskoff RM, Kennedy DN, Makris N, Berke JD et al (1997). Acute effects of cocaine on human brain activity and emotion. Neuron 19: 591-611.

Carr KD (2002). Augmentation of drug reward by chronic food restriction: behavioral evidence and underlying mechanisms. Physiol Behav 76: 353-364.
Carroll ME, Lac ST, Nygaard SL (1989). A concurrently available nondrug reinforcer prevents the acquisition or decreases the maintenance of cocaine-reinforced behavior. Psychopharmaco$\log$ y 97: 23-29.

Carroll ME, Morgan AD, Lynch WJ, Campbell UC, Dess NK (2002). Intravenous cocaine and heroin self-administration in rats selectively bred for differential saccharin intake: phenotype and sex differences. Psychopharmacology 161: 304-313.

Colby CR, Whisler K, Steffen C, Nestler EJ, Self DW (2003). Striatal cell type-specific overexpression of $\Delta$ FosB enhances incentive for cocaine. J Neurosci 23: 2488-2493.

Covington III HE, Miczek KA (2001). Repeated social-defeat stress, cocaine or morphine. Effects on behavioral sensitization and intravenous cocaine self-administration 'binges'. Psychopharmacology 158: 388-398.

Covington III HE, Miczek KA (2003). Vocalizations during withdrawal from opiates and cocaine: possible expressions of affective distress. Eur J Pharmacol 467: 1-13.

Doherty MD, Gratton A (1996). Medial prefrontal cortical D-1 receptor modulation of the meso-accumbens dopamine response to stress: an electrochemical study in freely-behaving rats. Brain Res 715: 86-97.

Fitch TE, Roberts DCS (1993). The effects of dose and access restrictions on the periodicity of cocaine self-administration in the rat. Drug Alcohol Depend 33: 119-128.

Gawin FH (1991). Cocaine addiction: psychology and neurophysiology. Science 251: 1580-1586.

Goeders NE (2002). The HPA axis and cocaine reinforcement. Psychoneuroendocrinology 27: 13-33.

Hammer Jr RP, Cooke ES (1996). Sensitization of neuronal response to cocaine during withdrawal following chronic treatment. NeuroReport 7: 2041-2045.

Haney M, Maccari S, Le Moal M, Simon H, Piazza PV (1995). Social stress increases the acquisition of cocaine self-administration in male and female rats. Brain Res 698: 46-52.

Herdegen T, Leah JD (1998). Inducible and constitutive transcription factors in the mammalian nervous system: control of gene expression by Jun, Fos and Krox, and CREB/ATF proteins. Brain Res Rev 28: 370-490.

Honkaniemi J, Zhang JS, Longo FM, Sharp FR (2000). Stress induces zinc finger immediate early genes in the rat adrenal gland. Brain Res 877: 203-208.

Jentsch JD, Taylor JR (1999). Impulsivity resulting from frontostriatal dysfunction in drug abuse: implications for the control of behavior by reward-related stimuli. Psychopharmacology 146: 373-390.

Kabbaj M, Norton CS, Kollack-Walker S, Watson SJ, Robinson TE, Akil $H$ (2001). Social defeat alters the acquisition of cocaine selfadministration in rats: role of individual differences in cocainetaking behavior. Psychopharmacology 158: 382-387.

Kollack-Walker S, Watson SJ, Akil H (1997). Social stress in hamsters: defeat activates specific neurocircuits within the brain. J Neurosci 17: 8842-8855.

Kreek MJ, Koob GF (1998). Drug dependence: stress and dysregulation of brain reward pathways. Drug Alcohol Depend 51: 23-47.

Lee JL, Everitt BJ, Thomas KL (2004). Independent cellular processes for hippocampal memory consolidation and reconsolidation. Science 304: 839-843.

Lucassen PJ, Vollmann-Honsdorf GK, Gleisberg M, Czeh B, De Kloet ER, Fuchs E (2001). Chronic psychosocial stress differentially affects apoptosis in hippocampal subregions and cortex of the adult tree shrew. Eur J Neurosci 14: 161-166.

Mantsch JR, Ho A, Schlussman SD, Kreek MJ (2001). Predictable individual differences in the initiation of cocaine self-administration by rats under extended-access conditions are dosedependent. Psychopharmacology 157: 31-39. 
Markou A, Koob GF (1991). Postcocaine anhedonia - an animal model of cocaine withdrawal. Neuropsychopharmacology 4: 17-26.

Martinez M, Calvo-Torrent A, Herbert J (2002). Mapping brain response to social stress in rodents with c-fos expression: a review. Stress 5: 3-13.

Miczek KA (1979). A new test for aggression in rats without aversive stimulation: differential effects of $d$-amphetamine and cocaine. Psychopharmacology 60: 253-259.

Miczek KA, Covington III HE, Nikulina EM, Hammer Jr RP (2004). Aggression and defeat: persistent effects on cocaine self-administration and gene expression in peptidergic and aminergic mesocorticolimbic circuits. Neurosci Biobehav Rev 27: 787-802.

Miczek KA, Mutschler NH (1996). Activational effects of social stress on IV cocaine self-administration in rats. Psychopharmacology 128: 256-264.

Miczek KA, Mutschler NH, Van Erp AMM, Blank AD, McInerney SC (1999a). $d$-Amphetamine 'cue' generalizes to social defeat stress: sensitization and role of accumbens dopamine. Psychopharmacology 147: 190-199.

Miczek KA, Nikulina E, Kream R, Carter G, Espejo E (1999b). Behavioral sensitization to cocaine after a brief social defeat stress: c-fos expression in the PAG. Psychopharmacology 141: 225-234.

Miczek KA, Thompson ML, Shuster L (1982). Opioid-like analgesia in defeated mice. Science 215: 1520-1522.

Miczek KA, Thompson ML, Tornatzky W (1991). Subordinate animals: behavioral and physiological adaptations and opioid tolerance. In: Brown MR (ed). Stress: Neurobiology and Neuroendocrinology. Marcel Dekker: New York. pp 323-357.

Miller RG (1981). Survival Analysis. John Wiley and Sons: New York.

Mutschler NH, Covington III HE, Miczek KA (2001). Repeated selfadministered cocaine 'binges' in rats: effects on cocaine intake and withdrawal. Psychopharmacology 154: 292-300.

Mutschler NH, Miczek KA (1998). Withdrawal from a selfadministered or non-contingent cocaine binge: differences in ultrasonic distress vocalizations in rats. Psychopharmacology 136: 402-408.

Mutschler NH, Miczek KA, Hammer Jr RP (2000). Reduction of zif/ 268 messenger RNA expression during prolonged withdrawal following 'binge' cocaine self-administration in rats. Neuroscience 100: $531-538$.

Nikulina EM, Covington III HE, Ganshow L, Hammer Jr RP, Miczek KA (2004). Long-term behavioral and neuronal crosssensitization to amphetamine induced by repeated brief social defeat stress: Fos in the ventral tegmental area and amygdala. Neuroscience 123: 857-865.

Nikulina EM, Hammer Jr RP, Miczek KA, Kream RM (1999). Social defeat stress increases expression of mu-opioid receptor mRNA in rat ventral tegmental area. NeuroReport 10: 3015-3019.

Nikulina EM, Marchand JE, Kream RM, Miczek KA (1998). Behavioral sensitization to cocaine after a brief social stress is accompanied by changes in fos expression in the murine brainstem. Brain Res 810: 200-210.

Pare D, Royer S, Smith Y, Lang EJ (2003). Contextual inhibitory gating of impulse traffic in the intra-amygdaloid network. Ann N Y Acad Sci 985: 78-91.

Parkinson JA, Robbins TW, Everitt BJ (2000). Dissociable roles of the central and basolateral amygdala in appetitive emotional learning. Eur J Neurosci 12: 405-413.

Parsons LH, Koob GF, Weiss F (1995). Serotonin dysfunction in the nucleus accumbens of rats during withdrawal after unlimited access to intravenous cocaine. J Pharmacol Exp Ther 274: 1182-1191.

Paxinos G, Watson C (1997). The Rat Brain in Stereotaxic Coordinates, 3rd edn. Academic Press: San Diego.
Perez-Jaranay JM, Vives F (1991). Electrophysiological study of the response of medial prefrontal cortex neurons to stimulation of the basolateral nucleus of the amygdala in the rat. Brain Res 564: 97-101.

Piazza PV, Deroche-Gamonent V, Rouge-Pont F, Le Moal M (2000). Vertical shifts in self-administration dose-response functions predict a drug-vulnerable phenotype predisposed to addiction. J Neurosci 20: 4226-4232.

Pierce RC, Kalivas PW (1997). A circuitry model of the expression of behavioral sensitization to amphetamine-like psychostimulants. Brain Res Rev 25: 192-216.

Quirk GJ, Likhtik E, Pelletier JG, Pare D (2003). Stimulation of medial prefrontal cortex decreases the responsiveness of central amygdala output neurons. J Neurosci 23: 8800-8807.

Remie R, van Dongen JJ, Rensema JW (1990). Permanent cannulation of the jugular vein (acc. to Steffens). In: van Dongen JJ (ed). Manual of Microsurgery on the Laboratory Rat. Elsevier: Amsterdam. pp 159-169.

Robinson TE, Gorny G, Mitton E, Kolb B (2001). Cocaine selfadministration alters the morphology of dendrites and dendritic spines in the nucleus accumbens and neocortex. Synapse 39: 257-266.

Rosenkranz JA, Grace AA (2001). Dopamine attenuates prefrontal cortical suppression of sensory inputs to the basolateral amygdala of rats. J Neurosci 21: 4090-4103.

Royer S, Martina M, Pare D (1999). An inhibitory interface gates impulse traffic between the input and output stations of the amygdala. J Neurosci 19: 10575-10583.

Sesack SR, Deutch AY, Roth RH, Bunney BS (1989). Topographical organization of the efferent projections of the medial prefrontal cortex in the rat: an anterograde tract-tracing study with Phaseolus vulgaris leucoagglutinin. J Comp Neurol 290: 213-242.

Sesack SR, Pickel VM (1992). Prefrontal cortical efferents in the rat synapse on unlabeled neuronal targets of catecholamine terminals in the nucleus accumbens septi and on dopamine neurons in the ventral tegmental area. J Comp Neurol 320: 145-160.

Sinha R (2001). How does stress increase risk of drug abuse and relapse? Psychopharmacology 158: 343-359.

Sokolove PG, Bushell WN (1978). The chi square periodogram: its utility for analysis of circadian rhythms. J Theor Biol 72: 131-160.

Stevenson CW, Gratton A (2003). Basolateral amygdala modulation of the nucleus accumbens dopamine response to stress: role of the medial prefrontal cortex. Eur J Neurosci 17: 1287-1295.

Thomas DA, Takahashi LK, Barfield RJ (1983). Analysis of ultrasonic vocalizations emitted by intruders during aggressive encounters among rats (Rattus norvegicus). J Comp Psychol 97: 201-206.

Tidey JW, Miczek KA (1996). Social defeat stress selectively alters mesocorticolimbic dopamine release: an in vivo microdialysis study. Brain Res 721: 140-149.

Tidey JW, Miczek KA (1997). Acquisition of cocaine selfadministration after social stress: role of accumbens dopamine. Psychopharmacology 130: 203-212.

Tornatzky W, Miczek KA (1993). Long-term impairment of autonomic circadian rhythms after brief intermittent social stress. Physiol Behav 53: 983-993.

Tornatzky W, Miczek KA (1994). Behavioral and autonomic responses to intermittent social stress: differential effects of clonidine and metoprolol. Psychopharmacology 116: 346-356.

Tornatzky W, Miczek KA (2000). Cocaine self-administration 'binges': transition from behavioral and autonomic regulation toward homeostatic dysregulation in rats. Psychopharmacology 148: 289-298.

van der Poel AM, Miczek KA (1991). Long ultrasonic calls in male rats following mating, defeat and aversive stimulation: frequency modulation and bout structure. Behaviour 119: 127-142. 
Von Holst D (1998). The concept of stress and its relevance for animal behavior. In: Moller AP, Milinsky M, Slater PJB (eds). Advances in the Study of Behavior. Academic Press: New York. pp 1-131.

Worley PF, Bhat RV, Baraban JM, Erickson CA, McNaughton BL, Barnes CA (1993). Thresholds for synaptic activation of transcription factors in hippocampus: correlation with longterm enhancement. J Neurosci 13: 4776-4786.

Worley PF, Christy BA, Nakabeppu Y, Bhat RV, Cole AJ, Baraban JM (1991). Constitutive expression of zif268 in neocortex is regulated by synaptic activity. Proc Natl Acad Sci USA 88: 5106-5110. 